\title{
ADSORÇÃO DE PRATA E COBRE POR ARGILA BENTONÍTICA: CARACTERIZAÇÃO DO ADSORVENTE PRÉ E PÓS PROCESSO
}

\author{
E. D. FREITAS ${ }^{1}$, A. C. R. CARMO ${ }^{1}$ A. F. ALMEIDA NETO ${ }^{1}$, M. G. A. VIEIRA ${ }^{1 *}$ \\ ${ }^{1}$ Universidade Estadual de Campinas, Faculdade de Engenharia Química \\ *e-mail: melissagav@feq.unicamp.br
}

\begin{abstract}
RESUMO
A remoção e recuperação de metais tóxicos de efluentes aquosos têm gerado grande interesse para pesquisas científicas. Nesse contexto, o processo de adsorção se mostra bastante promissor, possibilitando atingir níveis aceitáveis dessas substâncias nos meios aquosos, gerando, assim, a necessidade de estudar o potencial de novos adsorventes. Nesse trabalho, foi avaliada a argila bentonítica para remoção de íons de prata e cobre em mistura binária. A argila foi caracterizada antes e após a adsorção, para verificar a ocorrência de possíveis modificações no sólido, causadas pela presença dos íons metálicos. Dentre as análises empregadas estão a difração de Raio-X (DRX), a microscopia eletrônica de varredura (MEV), a fisissorção de $\mathrm{N}_{2}$ para obtenção da área superficial pelo método de BET (BET), análises termogravimétricas e termodiferenciais (TG/DTG e DTA), espectroscopia na região do infravermelho por Transformada de Fourier (FT-IR), e picnometria a gás Helio. Os resultados obtidos demonstraram que não ocorrem grandes alterações nas propriedades estruturais da partícula, mesmo após o processo de adsorção.
\end{abstract}

\section{INTRODUÇÃO}

A preservação e recuperação dos recursos naturais têm gerado grande preocupação a nível mundial. A água, recurso natural finito, é alvo de uso indiscriminado e, frequentemente, de altas taxas de contaminantes, sendo importante tratá-la de forma adequada para disposição no meio ambiente. Dentre as substâncias possíveis de serem encontradas nesse meio, estão os metais tóxicos, conhecidos pelos danos que podem causar à saúde e ao meio ambiente, quando em concentrações acima do permitido. (BARAKAT, 2011).

Dentre os metais tóxicos, destacam-se a prata e o cobre, metais possíveis de serem encontrados em conjunto em efluentes de processos de galvanoplastia (MOREIRA e CARVALHO, 2012). O cobre, apesar de essencial à saúde dos organismos vivos, pode trazer danos quando em concentrações muito elevadas, sendo considerado altamente tóxico para peixes e seres invertebrados (HOMEM, 2001). Já a prata apresenta elevada toxicidade, mesmo em baixas concentrações. O interesse sobre esse metal é, além de removê-lo, também recuperá-lo para reutilização por ser um metal nobre e de elevado valor agregado (ALLOWAY, 2010).

Para remoção de metais tóxicos de efluentes, diversos métodos são tradicionalmente empregados, como precipitação química, troca iônica, separação por membrana, entre outros. (KAPUR e MONDAL, 2014). Nessa conjuntura se insere a adsorção, processo que vem se destacando por apresentar bons resultados em eficiência, além de vantagens econômicas. (YUN et al., 2001). Também, os processos tradicionais 
podem apresentar muitas vezes operações inflexíveis ou ineficiência para atingir níveis reduzidos de contaminantes (LIU et al., 2010).

\subsection{Considerações Gerais Sobre a Adsorção}

O processo de adsorção é um fenômeno de superfície e se baseia na transferência de massa de uma substância presente na fase fluida (adsorbato) para a superfície de um sólido (adsorvente), dependente da diferença de concentrações entre as duas fases (BARAKAT, 2011). Nesse sentido, torna-se essencial a etapa de escolha do adsorvente e algumas características devem ser atendidas: remoção rápida e eficiente, baixo custo de manufatura e possibilidade de reutilização, partículas com tamanho, forma e propriedades mecânicas adequadas para uso em fluxo contínuo e alta seletividade para adsorção e dessorção do composto de interesse (BARROS, 2012).

As argilas vêm sendo estudadas como adsorvente, por apresentarem elevada capacidade de troca catiônica, grande área superficial específica, estabilidade mecânica e química, baixo custo e abundância (PADILLA-ORTEGA, 2013). Objeto de estudo desse trabalho, as argilas bentoníticas também apresentam a capacidade de aumentar seu volume na presença de umidade, facilidade de intercalação de compostos orgânicos e inorgânicos e boa resistência à temperatura e a solventes, gerando ainda mais interesse sobre seu uso (SILVA e FERREIRA, 2008).

Durante a adsorção, é importante caracterizar o adsorvente e verificar possíveis mudanças causadas pelo processo, a fim de avaliar melhor o sólido empregado. Para isso, no presente trabalho, diferentes técnicas foram empregadas, envolvendo a difração de Raio-X, microscopia eletrônica de varredura, fisissorção de $\mathrm{N}_{2}$ para obtenção da área superficial pelo método de BET (Brunauer, Emmett e Teller), análises termogravimétricas e termodiferenciais, espectroscopia na região do infravermelho por Transformada de Fourier e picnometria a gás Helio.

\section{MATERIAIS E MÉTODOS}

\subsection{Materiais utilizados}

O sólido adsorvente empregado no estudo foi a argila bentonítica Verde-lodo, proveniente do estado da Paraíba, no Brasil, e fornecida pela Dolomil Ltda. O material foi moído e peneirado para obtenção de diâmetro médio de $0,855 \mathrm{~mm} \mathrm{e}$, em seguida, foi submetido a um tratamento térmico para calcinação da amostra à $500^{\circ} \mathrm{C}$, a fim de aumentar sua estabilidade mecânica e resistência à fluidodinâmica. Como fonte de prata e cobre para as soluções em estudo, utilizaram-se os sais nitrato de prata e nitrato de cobre, fornecidos pela Merck (Alemanha) e pela Vetec (Brasil), respectivamente.

\subsection{Caracterização do adsorvente pré e pós adsorção}

A argila Verde-lodo calcinada foi caracterizada antes e após a adsorção, de modo a verificar possíveis mudanças estruturais causadas pelo processo. A argila foi contaminada com os íons metálicos prata e cobre em sistema batelada, na proporção de $1,0 \mathrm{~g}$ da argila para 1,0 L de solução contendo os metais, em agitação constante durante 16 horas, a fim de se obter o equilíbrio completo da adsorção. Para a etapa de caracterização, diferentes técnicas foram empregadas, como se segue.

\subsubsection{Difração de Raio-X}

A técnica de difração de Raio-X (DRX) foi empregada para se avaliar a estrutura cristalina do sólido. Para isso, utilizou-se equipamento Philips, modelo X'Pert-MPD, com radiação Ka do cobre, comprimento de onda $1,54 \AA$, voltagem de $40 \mathrm{kV}$, corrente de $40 \mathrm{~mA}, 2 \theta$ na faixa de 3 a $90^{\circ}$, com passo de $0,02^{\circ}$ e velocidade de $0,02^{\circ} / \mathrm{s}$. 


\subsubsection{Microscopia Eletrônica de Varredura}

Para analisar a topografia superficial do material adsorvente, realizou-se a microscopia eletrônica de varredura (MEV), em equipamento LEO, modelo LEO 440i. As amostras foram submetidas a ampliações de $50,100,500,1000$ e 2000 vezes.

\subsubsection{Fisissorção de $\mathrm{N}_{2}$}

A fisissorção de $\mathrm{N}_{2}$ foi empregada para se determinar a área superficial específica pelo método BET (Brunauer, Emmett e Teller), em equipamento Quantachrome, modelo NOVA1200e. As amostras foram tratadas termicamente a vácuo, a $300^{\circ} \mathrm{C}$, por cerca de 2 horas, para garantir a ausência de água ou qualquer outro condensado no adsorvente.

\subsubsection{Análises Térmicas}

Para analisar a estabilidade térmica do material, foram realizadas as análises termogravimétricas e termodiferenciais (TG/DTG e DTA), em equipamento Shimadzu, modelo DTG-60, desde a temperatura ambiente até $1000^{\circ} \mathrm{C}$, à $10^{\circ} \mathrm{C} / \mathrm{min}$.

2.2.5 Espectroscopia na Região do Infravermelho por Transformada de Fourier

A técnica de FT-IR foi empregada para se determinar os grupos funcionais presentes na amostra, em equipamento Thermo Scientific, modelo Niceolet 670 , na faixa de comprimento de onda de 4000 a $400 \mathrm{~cm}^{-1}$.

\subsubsection{Picnometria a gás He}

A densidade real da amostra foi determinada por picnometria a gás Helio, em equipamento Micrometics, modelo Accupyc 1330.

\section{RESULTADOS E DISCUSSÃO}

\subsection{Difração de Raio-X}

Os espectros de difração das amostras de argila Verde-lodo calcinada e contaminada com prata e cobre estão apresentados na Figura 1.

Figura 1 - Espectros de difração de Raios-X para argila Verde-lodo calcinada ${ }^{1}$ e contaminada com prata e cobre

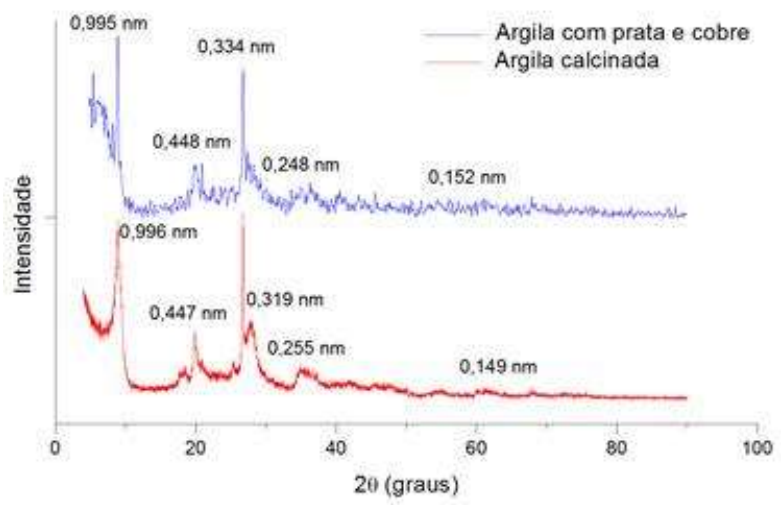

${ }^{1}$ Fonte: Almeida Neto (2011)

Nota-se da Figura 1 que não há alteração nos espectros encontrados para as argilas antes e após a adsorção. Os picos encontrados representam distâncias interplanares bastante semelhantes o que leva à conclusão de que as camadas lamelares da estrutura cristalina do sólido não foram alteradas.

Dentre os picos identificados, destacase o correspondente à distância interplanar $\mathrm{d}_{(001)}$, no valor de $0,995 \mathrm{~nm}$ e $0,996 \mathrm{~nm}$ para as argilas contaminada e calcinada, respectivamente. $\mathrm{O}$ valor esperado em argilas bentoníticas brutas é próximo a 1,5 nm (SANTOS, 1975), porém a calcinação da amostra pode ter modificado essa característica, como explicado por Almeida Neto (2011). Outros picos característicos de argilas bentoníticas podem ser identificados, como aqueles próximos a $0,448 \mathrm{~nm}$, típico de montmorilonitas; próximos a $0,334 \mathrm{~nm}$, da presença de quartzo (BRINDLEY e BROWN, 1980); próximos a $0,152 \mathrm{~nm}$, correspondentes à distância interplanar $\mathrm{d}_{(060)}$ e característicos da estrutura octaédrica da argila Verde-lodo (MOORE e REYNOLDS, 1997). 


\subsection{Microscopia Eletrônica de Varredura}

As micrografias obtidas com ampliação de 100x da argila calcinada e contaminada estão representadas na Figura 2.

Figura 2 - Micrografias da Verde-lodo: (a) argila calcinada com aumento $100 \mathrm{x}^{1}$, (b) argila contaminada com aumento $100 \mathrm{x}$

(a)

(b)
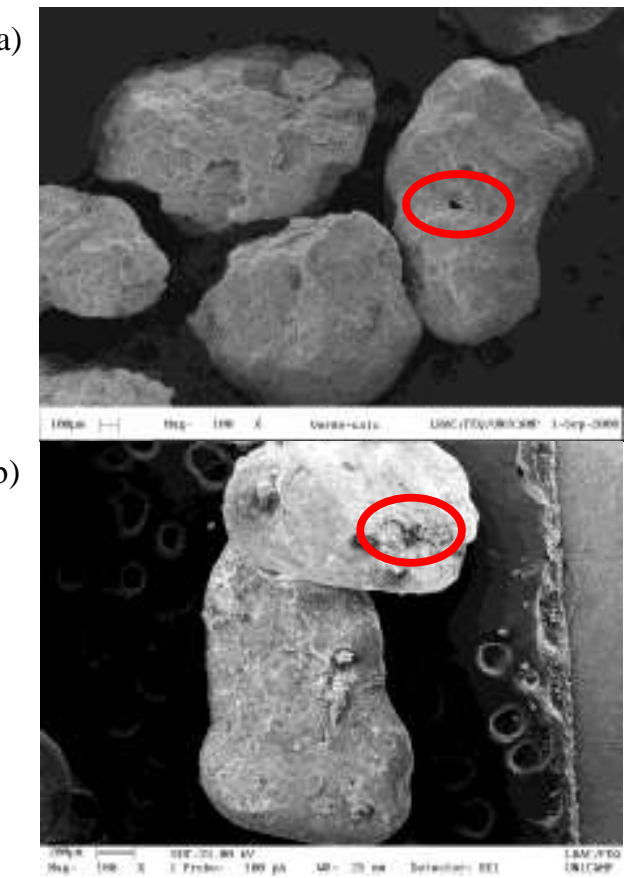

${ }^{1}$ Fonte: Almeida Neto (2011).

Ao se observar as imagens da Figura 2, nota-se irregularidades no tamanho das partículas antes e após a adsorção. É possível notar também a presença de macroporos visíveis em sua estrutura, identificados em vermelho nas micrografias. A Figura 3 indica micrografias obtidas em ampliação de 500x e confirmam a presença dos macroporos, também identificados em vermelho.

Figura 3 - Micrografias da Verde-lodo: (a) argila natural com aumento $500 \mathrm{x}^{1}$, (b) argila contaminada com aumento 500x (a)

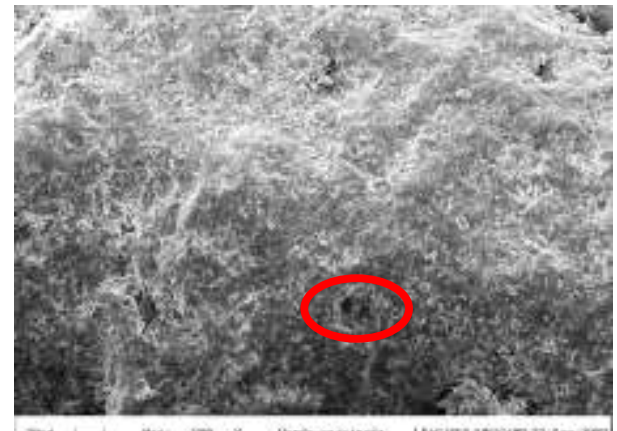

(b)

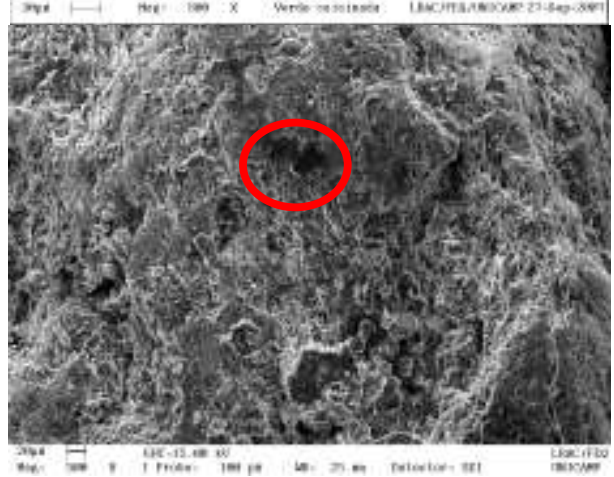

${ }^{1}$ Fonte: Almeida Neto (2011).

\subsection{Fisissorção de $\mathrm{N}_{2}$}

A análise por fisissorção de $\mathrm{N}_{2}$ possibilitou a obtenção da área superficial específica, determinada pelo método BET. A Tabela 1 apresenta esse resultado.

Tabela 1 - Área superficial obtida por BET.

\begin{tabular}{cc}
\hline Amostra & $\begin{array}{c}\text { Área Superficial } \\
\left(\mathrm{m}^{2} / \mathrm{g}\right)\end{array}$ \\
\hline Verde-lodo calcinada $^{1}$ & 81,060 \\
Verde-lodo contaminada $^{2}$ & 84,138 \\
\hline
\end{tabular}

${ }^{1}$ Fonte: Cantuaria (2014).

A área superficial apresentou um pequeno incremento após a adsorção, se mantendo, porém, na mesma ordem de grandeza. A técnica de fisissorção forneceu também a isoterma completa de adsorção/dessorção de $\mathrm{N}_{2}$, em função da variação da pressão relativa de 0,1 a 0,99 . A Figura 4 indica os perfis obtidos. 
Figura 4 - Isotermas de adsorção e dessorção de $\mathrm{N}_{2}$ para Verde-lodo calcinada ${ }^{1}$ e contaminada

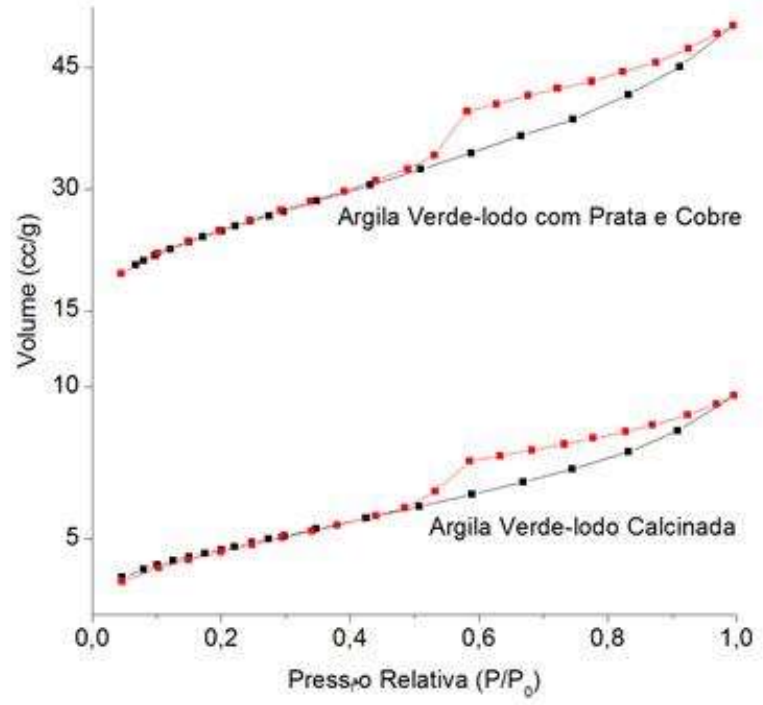

${ }^{1}$ Fonte: Cantuaria (2014).

O eixo vertical da Figura 4 foi ajustado de forma a facilitar a visualização dos dados obtidos. Pode-se observar o mesmo comportamento para ambas as amostras, com a presença de uma histerese. De acordo com a classificação da IUPAC (1982), obteve-se isoterma do tipo IV, característica para adsorventes industriais mesoporosos.

\subsection{Análises Térmicas}

As análises térmicas realizadas foram a termogravimétrica (TG) e sua derivada (DTG), representativas da variação de massa do sólido, em função do aquecimento da amostra; e a termodiferencial (DTA), que possibilita avaliar as transformações endo e exotérmicas. As curvas obtidas estão representadas nas Figuras 5(a) e 5(b) para as argilas calcinada e contaminada com prata e cobre, respectivamente.

Ao se comparar as curvas de perda de massa, representadas pela TG e DTG das Figuras 5(a) e 5(b), pode-se observar significativa semelhança entre a argila calcinada e a contaminada com prata e cobre. $\mathrm{O}$ primeiro pico, em $58{ }^{\circ} \mathrm{C}$ para a calcinada, se deslocou para $73{ }^{\circ} \mathrm{C}$ na argila após a adsorção. Porém, ambos se referem à perda de água da amostra. Já o segundo pico, em 565 ${ }^{\circ} \mathrm{C}$ na argila bruta, e $479{ }^{\circ} \mathrm{C}$ na argila contaminada, é referente à perda de hidroxilas (SANTOS, 1975).

Comparando-se então as curvas de DTA, ocorre certa semelhança no que se refere aos picos em $78{ }^{\circ} \mathrm{C}$ e $471^{\circ} \mathrm{C}$, na argila calcinada, e $89^{\circ} \mathrm{C}$ e $496^{\circ} \mathrm{C}$, na contaminada, todos esses representativos de transformações endotérmicas, com perda de água adsorvida e hidroxilas estruturais, respectivamente. Um pico duplo endo-exotérmico adicional é observado na argila após a adsorção, na região próxima a $900{ }^{\circ} \mathrm{C}$. Endotermicamente, tal pico está associado à destruição do reticulado cristalino, e exotermicamente, à formação de quartzo-alfa ou beta de mulita, conforme a natureza da argila. $\mathrm{Na}$ argila calcinada, observa-se uma queda brusca com tendência endotérmica na região próxima a $800{ }^{\circ} \mathrm{C}$, indicando fusão do material em questão (SANTOS, 1975).

Figura 5 - Análises TG/DTG e DTA para (a) argila calcinada ${ }^{1}$ e (b) argila contaminada com prata e cobre

(a)
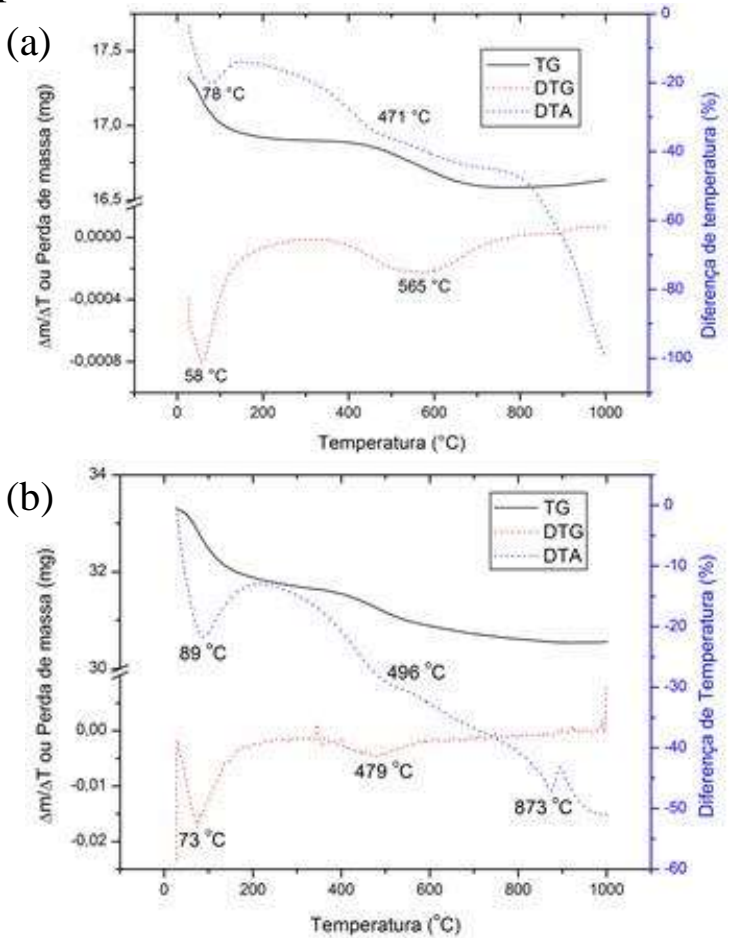

${ }^{1}$ Fonte: Almeida Neto (2011). 


\subsection{Espectroscopia na Região do Infravermelho por Transformada de Fourier}

A fim de identificar os grupos funcionais presentes na argila antes e após a adsorção, foi realizada espectroscopia na região do infravermelho (FT-IR). Os picos referentes aos grupos funcionais são identificados na Figura 6.

Figura 6 - Espectroscopia na região do infravermelho para argila calcinada ${ }^{1}$ e argila contaminada com prata e cobre

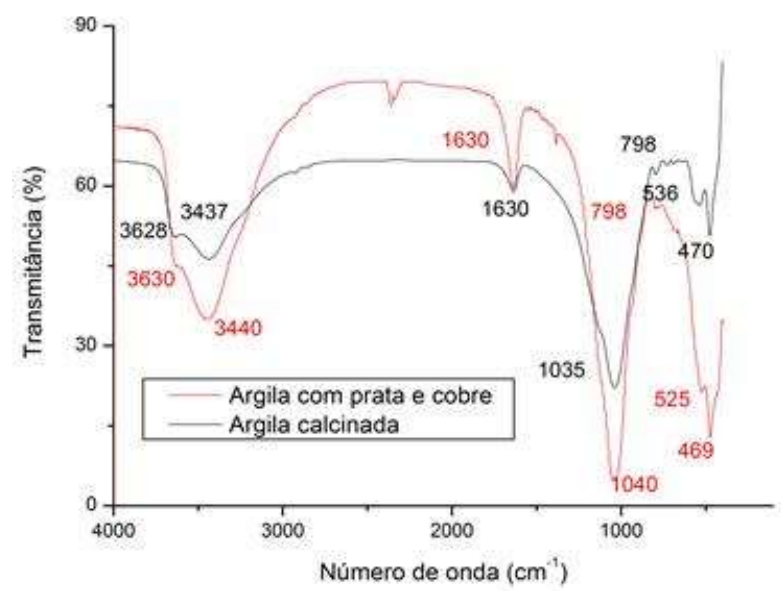

${ }^{1}$ Fonte: Almeida Neto (2011).

Os espectros obtidos para a argila antes e após a adsorção não apresentaram modificações em seus grupos funcionais. Os picos encontrados se referem em sua maioria à presença de água na argila e às características estruturais do sólido adsorvente. Os picos próximos a $3630 \mathrm{~cm}^{-1}$ indicam o estiramento $\mathrm{O}-\mathrm{H}$ de hidroxilas; aqueles próximos a $3440 \mathrm{~cm}^{-1}$ se referem ao estiramento $\mathrm{H}-\mathrm{O}-\mathrm{H}$; e os picos na região de $1630 \mathrm{~cm}^{-1}$ são referentes à flexão $\mathrm{O}-\mathrm{H}$ da água adsorvida. Já os picos próximos a $1040 \mathrm{~cm}^{-1} \mathrm{e}$ $798 \mathrm{~cm}^{-1}$ indicam o estiramento $\mathrm{Si}-\mathrm{O}$; os próximos a $525 \mathrm{~cm}^{-1}$ são referentes à flexão Al-O-Si; e os picos próximos a $469 \mathrm{~cm}^{-1}$ são representativos da flexão $\mathrm{Si}-\mathrm{O}-\mathrm{Si}$ (MADEJOVÁ e KOMADEL, 2001).

\subsection{Picnometria a gás Hélio}

A densidade real da argila Verde-lodo foi obtida por picnometria a gás Hélio, através da medida do volume total do sólido, considerando os poros existentes na amostra. Os resultados antes e após a adsorção se encontram na Tabela 2.

Tabela 2 - Densidade real da argila obtida por picnometria a gás Hélio

\begin{tabular}{cc}
\hline Amostra & $\begin{array}{c}\text { Densidade real } \\
\left(\mathrm{g} / \mathrm{cm}^{3}\right)\end{array}$ \\
\hline Verde-lodo calcinada $^{1}$ & 2,629 \\
Verde-lodo contaminada $^{1}$ & 2,501 \\
\hline
\end{tabular}

${ }^{1}$ Fonte: Cantuaria (2014).

Após o processo de adsorção em solução aquosa contendo os íons prata e cobre, é possível que a argila Verde-lodo tenha sofrido expansão, fazendo com que seus poros aumentassem e, consequentemente, a densidade real diminuísse. Isso foi observado nos dados da Tabela 2, com a densidade real reduzindo após a contaminação com prata e cobre.

\section{CONCLUSÕES}

A partir do estudo de caracterização da argila antes e após o processo de adsorção, foi possível observar que, de maneira geral, não ocorreram modificações significativas na estrutura ou morfologia do sólido adsorvente. Além disso, os grupos funcionais $\mathrm{e}$ a estabilidade térmica da amostra se mantiveram constantes, mesmo após o processo de adsorção de cobre e prata em argila bentonítica.

\section{REFERÊNCIAS}

ALLOWAY, B. J. Heavy metals in soil. United Kingdom: Springer, 2010.

ALMEIDA NETO, A. F., Caracterização e avaliação de argilas como adsorventes na 
remoção e eluição de íons cobre e mercúrio em diferentes sistemas. Tese (Doutorado em Engenharia Química) - Universidade Estadual de Campinas, Campinas, 2011.

BARAKAT, M. A. New trends in removing heavy metals from industrial wastewater. Arabian Journal of Chemistry, v. 4, p. 361377, 2011.

BARROS, A. M. Bioadsorção e dessorção dos íons $\mathrm{Cd}^{2+}, \mathrm{Cu}^{2+}, \mathrm{Ni}^{2+}, \mathrm{Pb}^{2+}$ e $\mathrm{Zn}^{2+}$ pela macrófita aquática azolla pinnata. Dissertação (Mestrado em Engenharia Química) - Universidade Estadual de Campinas, Campinas, 2012.

BRINDLEY, G. W., BROWN, G. E. Crystal Structures of Clay Minerals and their $\mathrm{X}$ Ray Indentification. London: Mineralogical Society, 1980.

CANTUARIA, M. L. Remoção de prata iônica monovalente por adsorção em argila bentonítica. Dissertação (Mestrado em Engenharia Química) - Universidade Estadual de Campinas, Campinas, 2014.

DAVRANCHE, M., LACOUR, S., BORDAS, F., BOLLINGER, J. C. An easy determinations of the surface chemical properties of simple and natural solids. Journal of Chemical Education, v.80, n.1, p.76-78, 2003.

HOMEM, E.M. Remoção de Chumbo, Níquel e Zinco em Zeólita Utilizando Sistema de Leito Fluidizado. Dissertação (Mestrado em Engenharia Química) Universidade Estadual de Campinas, Campinas, 2001.
IUPAC - International Union of Pure and Applied Chemistry. Reporting Physisorption Data for Gas/solid Systems with Special Reference to the Determination of Surface area and Porosity. Pure \& Applied Chemistry, v. 54, p. 2201-2218, 1982.

KAPUR, M., MONDAL, M.K. Competitive sorption of $\mathrm{Cu}$ (II) and $\mathrm{Ni}$ (II) ions from aqueous solutions: Kinetics, thermodynamics and desorption studies. Journal of the Taiwan Institute of Chemical Engineers, $n$. 45, p. 1803 - 1813, 2014.

LIU, Y., LI, H., ZHU, X. Competitive Adsorption of $\mathrm{Ag}+, \mathrm{Pb} 2+, \mathrm{Ni} 2+$, and $\mathrm{Cd} 2+$ Ions on Vermiculite. Separation Science and Technology, n. 45, p. 277 - 287, 2010.

MADEJOVÁ, J., KOMADEL, P. Baseline Studies of the Clay Minerals Society Source Clays: Infrared Methods. Clays and Clay Minerals, v. 49, n.5, p. 410-432, 2001.

MOORE, D. M., REYNOLDS JR, R. C. Xray Diffraction and the Identification and Analysis of Clay Minerals, 2.ed. New York: Oxford University Press, 1997.

MOREIRA, G.H., CARVALHO, L.M. Galvanoplastia. São Paulo:FATEC, 2012.

PADILLA-ORTEGA, E., LEYVA-RAMOS, R., FLORES-CANO, J.V. Binary adsorption of heavy metals from aqueous solution onto natural clays. Chemical Engineering Journal, n. 225, p. 535 - 546, 2013.

SANTOS, P. S. Tecnologia de Argilas Aplicada às Argilas Brasileiras, Volume 1 Fundamentos. São Paulo: Edgard Blücher Ltda, 1975. 
SILVA, A.R.V., FERREIRA, H.C. Argilas bentoníticas: conceitos, estruturas, propriedades, usos industriais, reservas, produção e produtores/ fornecedores nacionais e internacionais. Revista Eletrônica de Materiais e Processos, v. 3.2, p. $26-35,2008$.

YUN, Y-S., PARK, D., PARK, J.M., VOLESKY, B., Biosorption of trivalent chromium on the brow seaweed biomass. Environmental Science Technology, v. 35, p. 4353-4358, 2001.

\section{AGRADECIMENTOS}

Os autores agradecem à FAPESP (Processos no 2013/00732-1 e 2013/25212-0) pelo auxílio financeiro e bolsa concedida. 